\title{
Clinical development of TargomiRs, a miRNA mimic-based treatment for patients with recurrent thoracic cancer
}

miRNAs are responsible for post-transcriptional control of gene expression, and are frequently downregulated in cancer. It has become well established that restoring miRNA levels can inhibit tumor growth, and many studies have demonstrated this in preclinical models. This in turn has led to the first clinical trials of miRNA replacement therapy. This special report focuses on the development of TargomiRs - miRNA mimics delivered by targeted bacterial minicells - and the very first clinical experience of a miRNA replacement therapy in thoracic cancer patients in the Phase I MesomiR-1 trial.

First draft submitted: 5 April 2016; Accepted for publication: 3 May 2016; Published online: 17 May 2016

Keywords: EDVs • malignant pleural mesothelioma $\bullet$ mesomiR-1 $\bullet$ miRNA $\bullet$ miR-16

- targeted delivery

\section{miRNAs: a potential multi-targeted therapy for cancer}

Cancer is characterized by alterations in multiple cellular pathways, yet cancer therapy is based on a 'one target, one drug' model. A treatment effectively targeting multiple pathways simultaneously would be a major advance. Such an approach should not only more effectively inhibit cancer cell growth, but should also prevent loss of drug efficacy due to the common emergence of resistance in any single pathway. miRNAs have the potential to act in this way. These short noncoding RNAs are involved in post-transcriptional control of gene expression [1]. miRNAs form a complex network where each miRNA regulates multiple mRNAs and each mRNA is regulated by multiple miRNAs and this network of gene regulation contributes to the control of cell growth and maintenance of differentiation.

Given their involvement in basic cellular processes, it is unsurprising that miRNAs play an important role in cancer biology. An involvement of miRNA dysregulation in cancer was first demonstrated by the loss of the miR-15a/16-1 in chronic lymphocytic leu- kemia (CLL) [2]. Subsequent studies showed that the miRNA expression in tumors differed from the tissue of origin, that changes in miRNA expression are associated with the proliferation and drug resistance of cancer cells and that miRNAs can act as oncogenes or tumor suppressors [1,3]. As one important role of miRNAs is to maintain cells in their differentiated state, the global downregulation of miRNA expression observed in tumors and the frequent mutation in genes responsible for miRNA processing suggests that miRNA dysregulation plays an important role in the development of cancer [4].

With miRNA dysregulation contributing to many of the hallmarks of cancer [5], correcting miRNA expression represents an attractive therapeutic avenue for cancer patients. As miRNAs are most frequently downregulated in cancer [6], restoring the levels of deficient miRNA species is required. To date, therapeutic miRNA replacement has predominantly made use of synthetic miRNA mimics to restore lost tumor suppressor expression [7]. Restoration of lost tumor suppressor miRNAs using synthetic
Glen Reid ${ }^{1,2}$, Steven C Kao ${ }^{1,2,3}$, Nick Pavlakis ${ }^{4,5}$, Himanshu Brahmbhatt ${ }^{6}$, Jennifer MacDiarmid $^{6}$, Stephen Clarke ${ }^{4,5}$, Michael Boyer 2,3 \& Nico van Zandwijk ${ }^{* 1,2}$ ${ }^{1}$ Asbestos Diseases Research Institute, Concord, NSW 2139, Australia 2Sydney Medical School, The University of Sydney, Camperdown, NSW 2006, Australia

${ }^{3}$ Department of Medical Oncology, Chris O'Brien Lifehouse, Camperdown, NSW 2050, Sydney, Australia ${ }^{4}$ Kolling Institute of Medical Research, University of Sydney, St Leonards, NSW 2065, Australia ${ }^{5}$ Department of Medical Oncology, Royal North Shore Hospital, St Leonards, NSW 2065, Australia ${ }^{6}$ EnGenelC Ltd, Sydney, Australia *Author for correspondence: Tel.: +61297679800 Fax: +61297679860 nico.vanzandwijk@sydney.edu.au 
double-stranded RNAs (with a delivery agent) has been successful in preclinical models of a variety of tumors [8-14].

\section{miRNA-based drugs for thoracic cancers: preclinical studies}

Lung cancer was one of the first preclinical models in which a miRNA mimic-based therapy was tested. While numerous studies have investigated the effects of a range of different tumor suppressor miRNAs in thoracic cancer cell lines, relatively few have done so in preclinical animal models and fewer still have attempted systemic delivery (see Table 1). To date, the majority of these studies have focused on members of the let-7, miR-34 and miR-15/16 families [15].

Early work had shown that the let-7 family regulates the $R A S$ oncogene [16] and lung cancer cell growth [17]. Subsequently, the same group then used synthetic let$7 \mathrm{~b}$, either as a synthetic pre-miR-let-7b transfected pre-implantation or expressed from an adenovirus construct, to control lung cancer growth in vivo [18]. Subsequent work demonstrated that intratumoral injection of let-7b was able to control tumor growth through cell cycle inhibition [12]. Similarly, after several previous studies had demonstrated a role for miR-34a in controlling cancer cell growth, a synthetic mimic was shown to inhibit tumor growth in vivo following both intratumoral and intravenous (iv.) administration as a cationic lipid-based formulation [13]. The effects of miR-34a observed in these studies are due to its function as a master tumor suppressor via repression of multiple targets involved in the regulation of the cell cycle (e.g., CCND1, CDK6), apoptosis (BCL2, BIRC5) as well as well-known oncogenes (MET, MEK1, MYC; reviewed in [19]). Most recently these two groups teamed up to investigate delivery of let-7 or miR-34a mimics using a neutral lipid emulsion (NLE) [20]. Both approaches led to significant inhibition of lung tumor burden following eight systemic injections of NLE-formulated mimic. More recently, miR-29b [21], miR-200c [22] and a let-7/miR-34a combination [23] have been shown to have activity in lung cancer models following systemic delivery.

Our own preclinical studies have focused on malignant pleural mesothelioma (MPM). MPM is an incurable cancer affecting the pleura associated with previous asbestos exposure, and although the use of chemotherapy can reduce tumor burden and prolong life, more effective treatments are needed. We and others have investigated the expression of miRNAs in MPM and have observed the characteristic downregulation of tumor suppressor miRNAs typical of other cancers [24]. We noted a significant downregulation of miR-16 expression in tumor samples from patients who

\begin{tabular}{|c|c|c|c|c|}
\hline Tumor & miRNA & Delivery & Results & Ref. \\
\hline NSCLC & Let-7b & $\begin{array}{l}\text { Adenovirus } \\
\text { Cationic lipid, it. } \\
\text { Lentivirus } \\
\text { NLE, iv. }\end{array}$ & $\begin{array}{l}\text { Reduced xenograft growth; } 66 \% \text { reduction in } \\
\text { orthotopic tumor burden } \\
\text { Decreased tumor growth } \\
75 \% \text { reduction in tumor burden } \\
\text { Reduced orthotopic tumor burden }\end{array}$ & [12] \\
\hline NSCLC & miR-34 & $\begin{array}{l}\text { Cationic lipid, it. } \\
\text { and iv. } \\
\text { NLE, iv. }\end{array}$ & $\begin{array}{l}\text { Decreased xenograft growth } \\
60 \% \text { reduction in orthotopic tumor burden }\end{array}$ & [13] \\
\hline NSCLC & $\mathrm{miR}-200 \mathrm{c}$ & $\begin{array}{l}\text { Amphoteric } \\
\text { liposome }\end{array}$ & $\begin{array}{l}\text { miR-200c plus radiotherapy delayed xenograft } \\
\text { growth }\end{array}$ & [22] \\
\hline NSCLC & miR-29b & Liposomes, iv. & $60 \%$ smaller xenografts & [21] \\
\hline NSCLC & $\begin{array}{l}\text { Let-7b and } \\
\text { miR-34a }\end{array}$ & $\begin{array}{l}\text { NLE, iv. } \\
\text { Amphoteric } \\
\text { liposome, iv. }\end{array}$ & $\begin{array}{l}\text { Decreased orthotopic tumor burden with } \\
\text { combination } \\
40 \% \text { increased survival with combination or } \\
\text { miR-34a alone }\end{array}$ & $\begin{array}{l}{[23]} \\
{[23]}\end{array}$ \\
\hline MPM & miR-16 & EDVs, iv. & Dose-dependent inhibition of xenograft growth & [10] \\
\hline MPM & $\mathrm{miR}-34 \mathrm{~b} / \mathrm{c}$ & Adenovirus, it. & $55 \%$ sc. xenograft growth inhibition & [30] \\
\hline MPM & miR-193a-3p & EDVs, iv. & $70 \%$ sc. xenograft growth inhibition & [29] \\
\hline MPM/NSCLC & $\begin{array}{l}\text { Consensus } \\
\text { mimics }\end{array}$ & EDVs, iv. & $60-80 \%$ sc. xenograft growth inhibition & [32] \\
\hline
\end{tabular}


underwent extrapleural pneumonectomy [25]. Restoring expression of miR-16 in MPM cell lines in vitro and in vivo had a tumor-suppressive effect through induction of apoptosis [10]. This was shown in vitro to be related to a downregulation of the targets BCL2 and CCND1 among others. Changes in the expression of this miR family are also prevalent in CLL [2], prostate cancer [26] and NSCLC [27] and in these tumors, BCL2 and CCND1 were shown to be important targets [26,28]. In addition to miR-16, we have also demonstrated in vivo activity of miR-193a-3p mimics [29], which in vitro is related to downregulation of MCL1, and others have shown tumor growth inhibition following intratumoral injection of an adenoviral $\mathrm{miR}-34 \mathrm{~b} / \mathrm{c}$ vector [30].

Compared with normal mesothelium or mesothelial cell lines, consistent downregulation of not only miR-16, but the entire miR-15/107 group [31] was observed in both MPM tumors and cell lines. Based on this observation we developed synthetic miRNA mimics with novel sequences that are based on a consensus sequence derived from the miR-15/107 group [32]. The consensus mimics displayed greater growth inhibitory activity than native miR-16, and in preclinical studies the consensus mimics [32] controlled the growth of both MPM and NSCLC xenograft tumors.

\section{EDV ${ }^{\mathrm{TM}}$ nanocells: a novel drug-delivery method}

As an alternative to the liposomal or nanoparticlebased methods frequently used to deliver miRNAs, we employed $\mathrm{EDV}^{\mathrm{TM}}$ nanocells (EDVs). This bacterially derived delivery system developed by EnGeneIC Ltd (Sydney, Australia) [33] comprises nonviable minicells $400 \pm 20 \mathrm{~nm}$ in diameter produced by de-repressing polar sites of cell division in bacteria. Once loaded, EDVs are coated with bispecific antibody (BsAB) where one arm is available for binding to a receptor expressed on the surface of cancer cells. Following iv. administration, EDVs tend to accumulate in the tumor vasculature then bind to overexpressed target receptors on tumor cells and are thought to become involved in the endocytosis process. The EDV technology has been used in multiple preclinical studies to deliver chemotherapeutic agents [33], siRNAs [34] and miRNAs $[10,29,32,35]$ to tumors in vivo.

\section{miRNA-based drugs: translational into the clinic}

Despite obvious promise, translating preclinical findings has been hampered by inefficient delivery of miRNA mimics and has only recently made the jump to the clinic. The first clinical trial was initiated by Mirna Therapeutics (TX, USA) in 2013 and is focused on replacing miR-34a expression, thus building on the extensive preclinical studies already discussed. This single-arm Phase I safety study uses a proprietary miR34 a mimic delivered by a liposomal delivery agent dubbed Smarticles, and is being tested in patients with various advanced solid tumors and thus far has included three lung cancer patients. In interim results presented on 75 patients treated thus far, the treatment has produced two confirmed partial responses [36]. Phase II studies are anticipated in 2017.

\section{MesomiR-1: a Phase I trial of miRNA-based therapy for thoracic cancers}

The preclinical studies of EDV-mediated delivery of miRNA mimics led to the development of a protocol for Phase I testing of an experimental miRNA-based therapy in the MesomiR-1 trial. The therapy, dubbed TargomiRs, comprises patented miRNA mimics based on the miR-15/107 consensus sequence, packaged in EDVs that are targeted with an anti-EGFR-specific antibody. The trial was designed to test TargomiRs in patients with MPM or advanced NSCLC (ClinicalTrials.gov Identifier: NCT02369198). Guided by previous dose finding studies with EDVs [37,38] MesomiR-1 started testing $5 \times 10^{9}$ TargomiRs (20 min iv. infusion by standardized syringe pump, once a week) using a classical $3+3$ dose escalation design. TargomiR doses are batch prepared by EnGeneIC Ltd using patented miR-mimic sequences invented by ADRI. Following quality assurance/quality control, batches were divided into single dose volumes and freeze dried. Individual doses were reconstituted by EnGeneIC on the day of administration.

MesomiR-1 was initiated in December 2014 and nears completion. To date, 18 patients, all with MPM, have received different doses and schedules of TargomiRs, with data for the first six patients given in Figure 1 and toxicities associated with the infusions detailed in Table 2. In most patients infusion of TargomiRs was followed by rapidly transient inflammatory symptoms (shivering, rigor, temperature elevation) and a short period of lymphopenia/neutrophilia. Half experienced transient discomfort (pain) in the area of disease suggesting that TargomiRs reached their target. Overall TargomiR treatment has been well tolerated and shown to be safe in patients. Interim data indicates disease control was achieved in five of six patients after 8 weeks of protocol treatment (Figure 1).

Among the first six patients receiving 8 weekly doses of $5 \times 10^{9}$ TargomiRs there was one patient with a major objective response, as reported previously [39]. This patient had previously been treated with pleurodesis and two rounds of chemotherapy, but progressed after an initial partial response. After consenting to the 


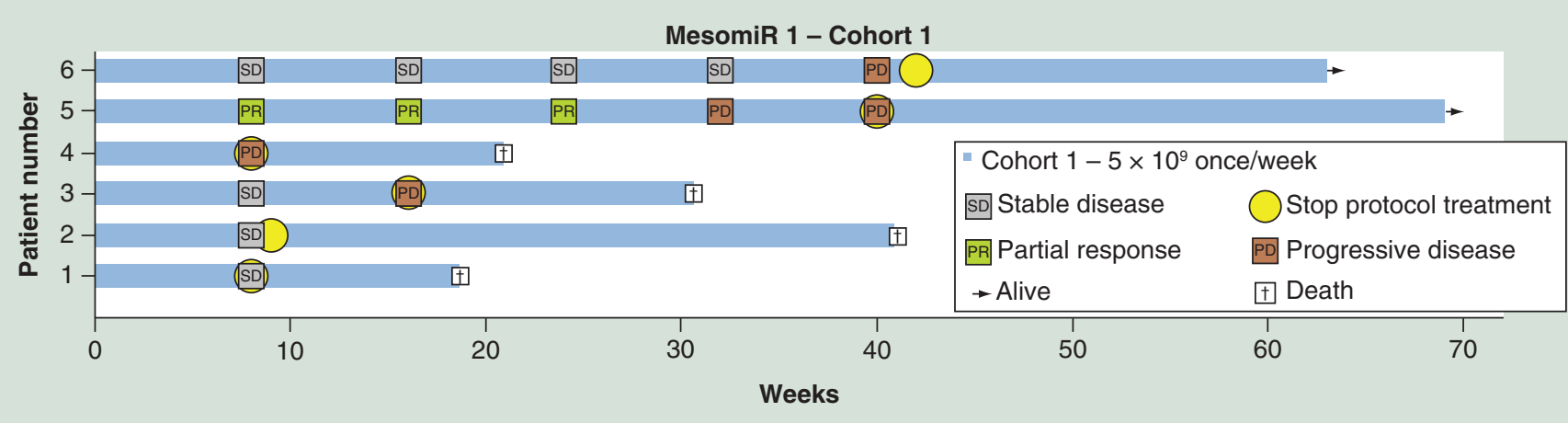

Figure 1. Swimmers plot of the first six patients treated with TargomiRs.

MesomiR-1 trial, he commenced TargomiR therapy at an adapted dose regimen owing to an elevated IL-6 blood level at baseline. He received $1 \times 10^{9}$ TargomiRs in the first week, $2 \times 10^{9}$ in the second week and $5 \times 10^{9}$ for the following 6 weeks. At the end of the 8-week treatment period, a partial response was noted on the chest CT (modified RECIST criteria; Figure 2) which was confirmed 4 weeks later. This patient continued TargomiR treatment for more than 40 weeks.

\section{Conclusion \& future perspective}

Two currently active Phase I clinical trials have provided early data confirming the activity of novel miRNAbased treatment approaches. Considering the fact that predominantly late-stage patients are invited to take part in Phase I studies, the partial responses observed are very promising. These support the continuation of ongoing Phase I trials as well as plans for future Phase II studies. For MesomiR-1 in particular, with an observed disease control rate of $65 \%$, there is great promise for future studies. In the case of TargomiRs, we plan to embark on Phase II studies within the next 12 months, with a randomized controlled trial comparing TargomiRs with second- or third-line chemotherapy a preferred option.

The MRX34 and MesomiR-1 trials are a first step on the road toward the realization of a miRNA-based therapy for cancer, but much work remains to be done. While promising, initial results suggest that these miRNAbased therapies will not be effective in all patients, and selecting those most likely to respond will be a major challenge. It is interesting to note that both the liposomal miR-34 and EDV-packaged consensus mimics elicit a marked inflammatory response. Both contain miRNA and it seems important to define the (potential) contributions of carriers and miRNA mimics to the inflammatory responses. Whether these inflammatory reactions are related to the response to TargomiRs will be addressed in biomarker studies linked to a planned

Table 2. Toxicities following TargomiR administration in the first six-patient cohort.

Clinical parameters

\begin{tabular}{|c|c|c|c|c|c|c|}
\hline & 1 & 2 & 3 & 4 & 5 & 6 \\
\hline Gender/age & $\mathrm{M} / 78$ & $\mathrm{~F} / 61$ & $\mathrm{M} / 52$ & $\mathrm{M} / 74$ & $\mathrm{M} / 53$ & $\mathrm{~F} / 68$ \\
\hline Pretreatment & $\begin{array}{l}\text { CT (2 lines) } \\
\text { and RT }\end{array}$ & $\mathrm{CT}$ (two lines) & $\begin{array}{l}\mathrm{CT} \text { (two lines) } \\
\text { and RT }\end{array}$ & CT (two lines) & $\mathrm{CT}$ (two lines) & $\begin{array}{l}\text { Chemotherapy } \\
\text { four lines }\end{array}$ \\
\hline Toxicity & $\begin{array}{l}\text { Chills and } \\
\text { rigor (G2) }\end{array}$ & $\begin{array}{l}\text { Chills and rigor } \\
\text { (G2) }\end{array}$ & Rigor (G2) & Rigor (G2) & Chills (G2) & $\begin{array}{l}\text { Pain at tumor } \\
\text { site (G2) }\end{array}$ \\
\hline (CTCAE Version 4) & - & $\begin{array}{l}\text { Pain at tumor } \\
\text { site (G3) }\end{array}$ & - & $\begin{array}{l}\text { Pain at tumor } \\
\text { site (G1) }\end{array}$ & - & - \\
\hline Laboratory & $\begin{array}{l}\text { Lymphopenia } \\
\text { (G4) }\end{array}$ & $\begin{array}{l}\text { Lymphopenia } \\
\text { (G4) }\end{array}$ & $\begin{array}{l}\text { Lymphopenia } \\
\text { (G4) }\end{array}$ & $\begin{array}{l}\text { Lymphopenia } \\
\text { (G4) }\end{array}$ & $\begin{array}{l}\text { Lymphopenia } \\
\text { (G3) }\end{array}$ & $\begin{array}{l}\text { Lymphopenia } \\
\text { (G3) }\end{array}$ \\
\hline Overall quality of life & Stable & $\begin{array}{l}\text { Slight } \\
\text { improvement }\end{array}$ & $\begin{array}{l}\text { Slight } \\
\text { improvement }\end{array}$ & Stable & $\begin{array}{l}\text { Major } \\
\text { improvement }\end{array}$ & Stable \\
\hline $\begin{array}{l}\text { Response (modified } \\
\text { RECIST) after } 8 \text { weeks }\end{array}$ & SD & SD & SD & $\begin{array}{l}\text { PD (+ second } \\
\text { primary) }\end{array}$ & $\begin{array}{l}\text { PR } \\
\text { (confirmed) }\end{array}$ & $\begin{array}{l}\text { SD (PR not } \\
\text { confirmed) }\end{array}$ \\
\hline Treatment duration & 8 weeks & 9 weeks & 16 weeks & 8 weeks & 40 weeks & 42 weeks \\
\hline
\end{tabular}


Phase II trial, which will focus on the signaling pathways active in different immune cell compartments.

Part of the attraction of using miRNAs for cancer therapy stems from their ability to target multiple genes in more than one cancer-related pathway simultaneously. Due to their wide-ranging impact on gene regulation; however, this also has the potential to lead to unwanted side effects in normal cells following nontargeted delivery, or in normal cells that are inadvertently targeted through expression of a cancer-related antigen. For miR-34a and miR-16, transfection of nontumor cells had little effect on cell growth [10,19], and formulated miR-34a mimic did not induce side effects in mice [19]. Nevertheless, some tumor suppressor miRNAs are overexpressed in other pathologies. For example, the miR-34 family is upregulated in heart disease where its inhibition seems to cardiac dysfunction [40,41]. Whether this dual function might have adverse consequences in cancer patients remains to be seen, but would seem unlikely due to the chronic nature of heart disease and the limited duration of the cancer therapy.

Recently, the inhibition of immune checkpoint inhibitors with antibody therapy has shown activity in thoracic cancer patients [42-44]. Interestingly, both miR-34a and miR-15/16 target the immune checkpoint protein PD-L1. In NSCLC patients, miR-34a and PD-L1 expression are inversely correlated, and upregulation of miR-34a via p53 expression reduces levels of PD-L1 in cell lines in vitro and in vivo when formulated as MRX34 [45]. Likewise, in MPM patients, we have shown an inverse correlation between expression levels of miR-15a/16 and PD-L1 in tumors [Reid G, Kao SC, van Zandwijk N, Unpublished Data]. Whether the association between miRNA expression and PD-L1 levels in tumors can be translated into a predictive marker of checkpoint inhibitor therapy requires further investigation.

Another commonality between miR-34a and miR-15/16 is their ability to be combined with other therapies. The use of miR-34a mimic was shown to synergize with the targeted agent erlotinib [14] as well as a let-7 mimic [23] in NSCLC cells in vitro, and to potentiate radiotherapy in a mouse model of lung cancer in vivo [22]. Similarly, we have seen that in vitro both miR-16 [10] and the consensus mimic [32] used in the clinical trial can sensitize MPM cells to pemetrexed and cisplatin, two chemotherapy drugs frequently used in treatment of MPM

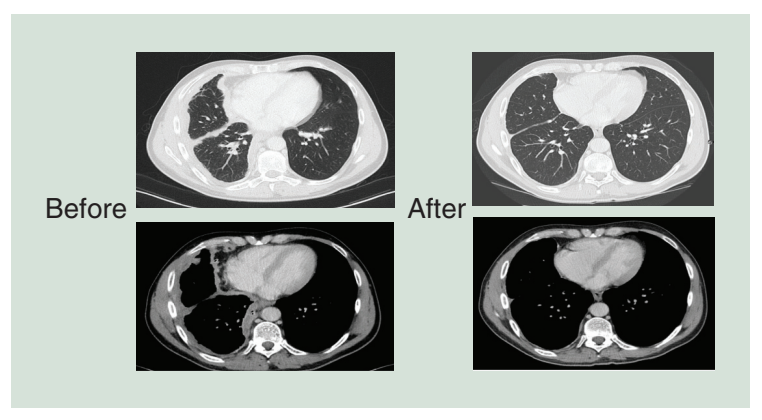

Figure 2. Computed tomography scans from patient 5 before (left) and after 8 weeks (right) of TargomiR treatment, showing a partial response.

Reprinted with permission from [39] () American Thoracic Society (2016).

patients. Such combinations are obvious to explore in future clinical trials involving miRNA therapies.

Continuing studies in the coming years will provide important new data allowing us to better understand the activity of miRNA-based drugs, and the role of the individual components of these drugs in eliciting an immune reaction. Along with efforts to understand which patients are more likely to benefit from miRNA replacement, this will bring miRNA therapeutics closer to the clinic.

\section{Financial and competing interests disclosure}

Research in the authors' laboratories is supported by a Translational Program Grant from the Cancer Institute NSW (11TPG3-06 to N van Zandwijk, G Reid, SC Kao and N Pavlakis) and the Cancer Council NSW (RG14-17 to G Reid, N van Zandwijk, J MacDiarmid and $\mathrm{H}$ Brahmbhatt). G Reid and N van Zandwijk are holders of a patent covering consensus mimics. $J$ MacDiarmid and $\mathrm{H}$ Brahmbhatt are Co-Directors and shareholders in EnGenelC Ltd. The authors have no other relevant affiliations or financial involvement with any organization or entity with a financial interest in or financial conflict with the subject matter or materials discussed in the manuscript apart from those disclosed.

No writing assistance was utilized in the production of this manuscript.

\section{Open access}

This work is licensed under the Attribution-NonCommercialNoDerivatives 4.0 Unported License. To view a copy of this license, visit http://creativecommons.org/licenses/by-nc-nd/4.0/

\section{Executive summary}

- Multiple tumor suppressor miRNAs are able to inhibit proliferation of lung cancer and mesothelioma cells in vitro and in vivo.

- Preclinical studies reveal systemic delivery of miRNA mimics via EDV ${ }^{\mathrm{TM}}$ nanocells to have therapeutic potential for thoracic cancer treatment.

- The ongoing Phase I MesomiR-1 trial has treated 18 mesothelioma patients to date. In the first six patients, one patient had a partial response and four had stable disease after 8 weeks. 


\section{References}

Papers of special note have been highlighted as:

- of interest; $\bullet \bullet$ of considerable interest

1 Garzon R, Calin GA, Croce CM. MicroRNAs in cancer. Annu. Rev. Med. 60 167-179 (2009).

2 Bichi R, Shinton SA, Martin ES et al. Human chronic lymphocytic leukemia modeled in mouse by targeted TCL1 expression. Proc. Natl Acad. Sci. USA 99(10), 6955-6960 (2002).

3 Lee YS, Dutta A. MicroRNAs in cancer. Annu. Rev. Pathol. 4, 199-227 (2009).

4 Kasinski AL, Slack FJ. Epigenetics and genetics. MicroRNAs en route to the clinic: progress in validating and targeting microRNAs for cancer therapy. Nat. Rev. Cancer 11(12), 849-864 (2011).

5 Hanahan D, Weinberg RA. Hallmarks of cancer: the next generation. Cell 144(5), 646-674 (2011).

6 Lu J, Getz G, Miska EA et al. MicroRNA expression profiles classify human cancers. Nature 435(7043), 834-838 (2005).

7 Henry JC, Azevedo-Pouly AC, Schmittgen TD. MicroRNA replacement therapy for cancer. Pharm. Res. 28(12), 3030-3042 (2011).

8 Akao Y, Nakagawa Y, Hirata I et al. Role of anti-oncomirs miR-143 and -145 in human colorectal tumors. Cancer Gene Ther. 17(6), 398-408 (2010).

9 Ibrahim AF, Weirauch U, Thomas M, Grunweller A, Hartmann RK, Aigner A. MicroRNA replacement therapy for miR-145 and miR-33a is efficacious in a model of colon carcinoma. Cancer Res. 71(15), 5214-5224 (2011).

10 Reid G, Pel ME, Kirschner MB et al. Restoring expression of miR-16: a novel approach to therapy for malignant pleural mesothelioma. Ann. Oncol. 24(12), 3128-3135 (2013).

-• The first study to use EDVTM nanocells (EDVs) to deliver miRNA mimics in vivo.

11 Takeshita F, Patrawala L, Osaki M et al. Systemic delivery of synthetic microRNA-16 inhibits the growth of metastatic prostate tumors via downregulation of multiple cell-cycle genes. Mol. Ther. 18(1), 181-187 (2010).

12 Trang P, Medina PP, Wiggins JF et al. Regression of murine lung tumors by the let-7 microRNA. Oncogene 29(11), 1580-1587 (2010).

13 Wiggins JF, Ruffino L, Kelnar K et al. Development of a lung cancer therapeutic based on the tumor suppressor microRNA-34. Cancer Res. 70(14), 5923-5930 (2010).

14 Zhao J, Kelnar K, Bader AG. In-depth analysis shows synergy between erlotinib and miR-34a. PLoS ONE 9(2), e89105 (2014).

15 Fortunato O, Boeri M, Verri C, Moro M, Sozzi G. Therapeutic use of microRNAs in lung cancer. Biomed. Res. Int. 2014, 756975 (2014).

16 Johnson SM, Grosshans H, Shingara J et al. RAS is regulated by the let-7 microRNA family. Cell 120(5), 635-647 (2005).

17 Johnson CD, Esquela-Kerscher A, Stefani G et al. The let-7 microRNA represses cell proliferation pathways in human cells. Cancer Res. 67(16), 7713-7722 (2007).
18 Esquela-Kerscher A, Trang P, Wiggins JF et al. The let-7 microRNA reduces tumor growth in mouse models of lung cancer. Cell Cycle 7(6), 759-764 (2008).

19 Bader AG. miR-34 - a microRNA replacement therapy is headed to the clinic. Front. Genet. 3, 120 (2012).

20 Trang P, Wiggins JF, Daige CL et al. Systemic delivery of tumor suppressor microRNA mimics using a neutral lipid emulsion inhibits lung tumors in mice. Mol. Ther. 19(6), 1116-1122 (2011).

21 Wu Y, Crawford M, Mao Y et al. Therapeutic delivery of microRNA-29b by cationic lipoplexes for lung cancer. Mol. Ther. Nucleic Acids 2 e84 (2013).

22 Cortez MA, Valdecanas D, Zhang X et al. Therapeutic delivery of miR-200c enhances radiosensitivity in lung cancer. Mol. Ther. 22(8), 1494-1503 (2014).

23 Kasinski AL, Kelnar K, Stahlhut C et al. A combinatorial microRNA therapeutics approach to suppressing non-small cell lung cancer. Oncogene 34(27), 3547-3555 (2015).

24 Birnie KA, Yip YY, Ng DC et al. Loss of miR-223 and JNK signaling contribute to elevated stathmin in malignant pleural mesothelioma. Mol. Cancer Res. 13(7), 1106-1118 (2015).

25 Kirschner MB, Cheng YY, Badrian B et al. Increased circulating miR-625-3p: a potential biomarker for patients with malignant pleural mesothelioma. J. Thorac. Oncol. 7(7), 1184-1191 (2012).

26 Bonci D, Coppola V, Musumeci M et al. The miR-15a-miR-16-1 cluster controls prostate cancer by targeting multiple oncogenic activities. Nat. Med. 14(11), 1271-1277 (2008).

27 Bandi N, Zbinden S, Gugger M et al. miR-15a and miR-16 are implicated in cell cycle regulation in a Rb-dependent manner and are frequently deleted or down-regulated in non-small cell lung cancer. Cancer Res. 69(13), 5553-5559 (2009).

28 Cimmino A, Calin GA, Fabbri M et al. miR-15 and miR-16 induce apoptosis by targeting BCL2. Proc. Natl Acad. Sci. USA 102(39), 13944-13949 (2005).

29 Williams M, Kirschner MB, Cheng YY et al. miR-193a-3p is a potential tumor suppressor in malignant pleural mesothelioma. Oncotarget 6(27), 23480-23495 (2015).

30 Ueno T, Toyooka S, Fukazawa T et al. Preclinical evaluation of microRNA-34b/c delivery for malignant pleural mesothelioma. Acta Med. Okayama 68(1), 23-26 (2014).

31 Finnerty JR, Wang WX, Hebert SS, Wilfred BR, Mao G, Nelson PT. The miR-15/107 group of microRNA genes: evolutionary biology, cellular functions, and roles in human diseases. J. Mol. Biol. 402(3), 491-509 (2010).

32 Reid GWM, Kirschner Mb, Mugridge $\mathrm{N}$ et al. Targeted delivery of a synthetic microRNA-based mimic as an approach to cancer therapy. Cancer Res. 75 (Suppl. 15), Abstract 3976 (2015).

33 MacDiarmid JA, Mugridge NB, Weiss JC et al. Bacterially derived $400 \mathrm{~nm}$ particles for encapsulation and cancer cell targeting of chemotherapeutics. Cancer Cell 11(5), 431-445 (2007).

•• Describes in detail the EDV delivery system. 
34 MacDiarmid JA, Amaro-Mugridge NB, Madrid-Weiss J et al. Sequential treatment of drug-resistant tumors with targeted minicells containing siRNA or a cytotoxic drug. Nat. Biotechnol. 27(7), 643-651 (2009).

Glover AR, Zhao JT, Gill AJ et al. microRNA-7 as a tumor suppressor and novel therapeutic for adrenocortical carcinoma. Oncotarget 6(34), 36675-36688 (2015).

Beg MS, Brenner A, Sachdev J et al. Safety, tolerability, and clinical activity of MRX34, the first-in-class liposomal miR-34 mimic, in patients with advanced solid tumors. Presented at: AACR-NCI-EORTC International Conference on Molecular Targets and Cancer Therapeutics. Boston, MA, USA, 5-9 November 2015.

37 Solomon BJ, Desai J, Rosenthal M et al. A first-time-inhuman Phase I clinical trial of bispecific antibody-targeted, paclitaxel-packaged bacterial minicells. PLoS ONE 10(12), e0144559 (2015).

- A first-in-man study describing the safety of drug-loaded EDVs.

38 Whittle JR, Lickliter JD, Gan HK et al. First in human nanotechnology doxorubicin delivery system to target epidermal growth factor receptors in recurrent glioblastoma. J. Clin. Neurosci. 22(12), 1889-1894 (2015).

- A second study showing the safety of drug-loaded EDVs in patients.

39 Kao SC, Fulham M, Wong Ket al. A significant metabolic and radiological response after a novel targeted
microRNA-based treatment approach in malignant pleural mesothelioma. Am. J. Respir. Crit. Care Med. 191(12), 1467-1469 (2015).

-. Details the first reported response in a patient treated with a miRNA-based therapy.

40 Bernardo BC, Gao XM, Tham YK et al. Silencing of miR-34a attenuates cardiac dysfunction in a setting of moderate, but not severe, hypertrophic cardiomyopathy. PLoS ONE 9(2), e90337 (2014).

41 Bernardo BC, Gao XM, Winbanks CE et al. Therapeutic inhibition of the miR-34 family attenuates pathological cardiac remodeling and improves heart function. Proc. Natl Acad. Sci. USA 109(43), 17615-17620 (2012).

42 Alley EW ML, Santoro A, Beckey K et al. Clinical safety and efficacy of pembrolizumab (MK-3475) in patients with malignant pleural mesothelioma: preliminary results from KEYNOTE-028. Cancer Res. 75(Suppl. 15), Abstract CT103 (2015).

43 Borghaei H, Paz-Ares L, Horn L et al. Nivolumab versus docetaxel in advanced nonsquamous non-small-cell lung cancer. N. Engl. J. Med. 373(17), 1627-1639 (2015). Brahmer J, Reckamp KL, Baas P et al. Nivolumab versus docetaxel in advanced squamous-cell non-small-cell lung cancer. N. Engl. J. Med. 373(2), 123-135 (2015).

45 Cortez MA, Ivan C, Valdecanas D et al. PDL1 regulation by p53 via miR-34. J. Natl Cancer Inst. 108(1), djv303 (2016). 